\title{
ANTI-HYPERTENSIVE DRUGS HAVE DIFFERENT EFFECTS ON VENTRICULAR HYPERTROPHY REGRESSION
}

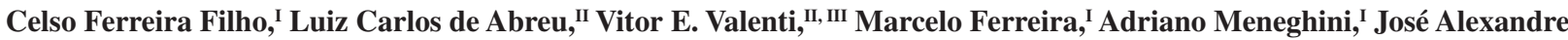 \\ Silveira, ${ }^{\mathrm{I}}$ Andrés R. Pérez Riera, ${ }^{\mathrm{I}}$ Eduardo Colombari, ${ }^{\mathrm{II}}$ Neif Murad, ${ }^{\mathrm{I}}$ Paulo Roberto Santos-Silva, ${ }^{\mathrm{I}}$ Lovian José Henrique \\ Pereira da Silva, ${ }^{\mathrm{I}}$ Luiz Carlos Marques Vanderlei, ${ }^{\mathrm{IV}}$ Tatiana D. Carvalho, ${ }^{\mathrm{II}}$ Celso Ferreira, $\mathrm{III}$
}

doi: $10.1590 / \mathrm{S} 1807-59322010000700012$

Ferreira Filho C, Abreu LC, Valenti VE, Ferreira M, Meneghini A, Silveira JA et al. Anti-hypertensive drugs have different effects on ventricular hypertrophy regression. Clinics. 2010;65(7):723-8.

OBJECTIVES: There is a direct relationship between the regression of left ventricular hypertrophy (LVH) and a decreased risk of mortality. This investigation aimed to describe the effects of anti-hypertensive drugs on cardiac hypertrophy through a metaanalysis of the literature.

METHODS: The Medline (via PubMed), Lilacs and Scielo databases were searched using the subject keywords cardiac hypertrophy, antihypertensive and mortality. We aimed to analyze the effect of anti-hypertensive drugs on ventricle hypertrophy. RESULTS: The main drugs we described were enalapril, verapamil, nifedipine, indapamina, losartan, angiotensin-converting enzyme inhibitors and atenolol. These drugs are usually used in follow up programs, however, the studies we investigated used different protocols. Enalapril (angiotensin-converting enzyme inhibitor) and verapamil ( $\mathrm{Ca}^{++}$channel blocker) caused hypertrophy to regress in LVH rats. The effects of enalapril and nifedipine $\left(\mathrm{Ca}^{++}\right.$channel blocker) were similar. Indapamina (diuretic) had a stronger effect than enalapril, and losartan (angiotensin II receptor type 1 (AT1) receptor antagonist) produced better results than atenolol (selective 1 receptor antagonist) with respect to LVH regression.

CONCLUSION: The anti-hypertensive drugs induced various degrees of hypertrophic regression.

KEYWORDS: Hypertrophy; Cardiomyopathy; Hypertrophic; Left ventricle hypertension; Cardiology.

\section{INTRODUCTION}

Cardiac hypertrophy consists of an increase in myocardial mass that results in persistent pressure and/ or volume overload. ${ }^{1}$ In myocytes, hyperplasia is limited because of the cells' differentiated profile, that most closely resembles a short period of time that ends immediately after birth. ${ }^{1}$ The high prevalence of ventricular dysfunction is

\footnotetext{
${ }^{\text {I }}$ Departamento de Clínica Médica, Disciplina de Cardiologia, Faculdade de Medicina do ABC - Santo André/SP, Brasil.

II Departamento de Morfologia e Fisiologia, Faculdade de Medicina do ABC - Santo André/SP, Brasil.

III Departamento de Medicina, Disciplina de Cardiologia, Universidade Federal de São Paulo (UNIFESP) - São Paulo/SP, Brasil.

IV Departamento de Fisioterapia da Faculdade de Ciências e Tecnologia, Universidade Estadual Paulista ( FCT - UNESP) - Presidente Prudente/ SP, Brasil.

Email: celsoferreira.dmed@epm.br / ferreira-celso@uol.com.br

Tel.: 5511 4993-5403

Received for publication on April 01, 2010

First review completed on April 06, 2010

Accepted for publication on April 06, 2010
}

used to support the view that the ability to regenerate after injury is not significant. However, research has shown that myocyte regeneration is fundamental to heart homeostasis. ${ }^{2}$ For instance, during aortic stenosis, the combination of hypertrophy and hyperplasia increases cardiac mass ${ }^{3}$ at specific locations, such as the site of a therapeutic stem cell implant. $^{2}$

Remodeling manifests itself in almost all cardiac diseases and was initially considered beneficial because it compensates for the increased hemodynamic overload and ventricular wall stress and optimizes both function and energy expenditure. ${ }^{1}$ In some circumstances, remodeling is also considered to be an adaptive phenomenon that increases heart performance during work overload. This phenomenon is a result of protein synthesis and either the incorporation of new units into contractile myocytes or the addition of new sarcomeres. ${ }^{3}$ Nevertheless, the benefits of this process are limited by the rate of maintenance, which promotes deleterious changes characterizing this feature as uniquely unfavorable. ${ }^{4}$ 
The mechanisms leading to myocardial injuries ${ }^{5-9}$ and hypertrophy ${ }^{10-12}$ during physiological or pathological states are different. For instance, the pathological hypertrophy results from the interaction of mechanical forces and neural and hormonal factors. Hemodynamic overload promotes myocyte stretch, the release of intracellular calcium, the activation of calcineurin and the induction of gene expression reprogramming. ${ }^{1}$ In athletes, left ventricular hypertrophy $(\mathrm{LVH})$ is regarded as a physiological response that results from a hemodynamic overload; this physiological response does not result in the harmful effects of hypertension development or other heart diseases. ${ }^{10-12}$ The literature explains physiological LVH as the result of a volume and pressure overload that results from intense physical training (the hemodynamic stimulus), which is not necessarily accompanied by neural and humoral changes. ${ }^{13}$

Despite some initial benefits of physiological hypertrophy, it is difficult to determine the time at which physiological hypertrophy becomes pathological ${ }^{1}$ and represents a significant morbidity and mortality risk. In other words, it is difficult to pinpoint exactly when, during the natural development of hypertension, cardiac hypertrophy raises an individual's risk of experiencing a cardiovascular event by a reported factor of six to eight times. ${ }^{3}$

There are well-known associations between LVH and several conditions, such as obesity, diabetes, myocardial infarction and even mild elevation in blood pressure, ${ }^{1}$ as well as other cardiovascular risk factors that may be associated with increased cardiac mass regardless of ventricular pressure. Therefore, LVH is a powerful predictor of cardiovascular morbidity and mortality. ${ }^{3}$ Clinical and experimental studies have reported that several pharmacological, hemodynamic and non-hemodynamic factors are able to induce, reverse and prevent $\mathrm{LVH},{ }^{14-16}$ interstitial fibrosis ${ }^{17}$ and the progression of atherosclerotic effects on myocytes. ${ }^{18}$ Clinically, cardiac hypertrophy is associated with increased adverse events, including stroke, chronic renal failure, ventricular dysfunction, ventricular arrhythmias and sudden death. ${ }^{3}$ Cardiac hypertrophy is also associated with a higher prevalence of coronary disease and is related to endothelial dysfunction. This dysfunction may lead to myocardial ischemia, even in the absence of epicardial artery obstruction, by reducing coronary flow reserves due to various hemodynamic factors, such as a minimal reduction in coronary resistance, systolic coronary perivascular compression, collagen deposition, fibrosis and a lower production of local vasodilator substances, such as nitric oxide. ${ }^{19}$

After adjusting for other risk factors, Koren and coworkers ${ }^{20}$ reported a positive relationship between ventricular mass and geometry with the morbidity and mortality of patients who did not have complicated hypertension. ${ }^{20}$ The Framingham Heart Study, published by Levy et $\mathrm{al}^{21}$ included 3,220 healthy subjects aged 40 years or older. This study demonstrated that estimating left ventricular mass by echocardiography can provide prognostic information about cardiovascular risk and can predict negative cardiovascular-related clinical events, including death. ${ }^{21}$ Moreover, LVH increased the risk of major cardiovascular events in $40 \%$ of the patients enrolled in the study. $^{21}$

From these previous investigations, we infer that LVH constitutes an ominous risk factor for cardiovascular disease and that the magnitude of this risk is directly related to morbidity and mortality rates. Therefore, in this study, we endeavored to describe the effects of anti-hypertensive drugs on cardiac hypertrophy by a meta-analysis of previous studies.

\section{METHODS}

The Medline (via PubMed), Lilacs and Scielo databases were searched using the following subject keywords: "cardiac hypertrophy," "antihypertensive" and "mortality." We also used the "related articles" function on PubMed, Lilacs and Scielo, which allowed us to search the references of the studies that were retrieved during our search. Publications were included in our review if either their titles or abstracts were available in English or Portuguese and suggested any effect (i.e., beneficial or malefic) or lack thereof from an anti-hypertensive treatment on cardiac hypertrophy. The review was completed in March, 2010. Publications were excluded if the treatment was limited to a particular technique or if the population received only one specific procedure (drug treatment) associated with a disease state or an age group. Other studies on anti-hypertensive treatment for hypertensive patients that offered additional relevant information found in the same database were also examined. Each publication was reviewed to identify the author(s), study period and data source, which influenced us to include the reference in the study.

\section{RESULTS}

A total of 694 manuscripts met the inclusion criteria for our study. We excluded investigations in which treatment was limited to a particular method and those studies in which the study population was limited to patients who were undergoing a particular procedure or an associated disease state.

In Table 1, we summarize studies that evaluated the relationship between anti-hypertensive drugs and cardiac hypertrophy. The investigations included in Table 
Table 1 - A summary of the main clinical and experimental studies for anti-hypertensive drugs and left ventricular hypertrophy (LVH).

\begin{tabular}{ll}
\hline Author and year & Main finding $(s)$ \\
\hline Costa et al., $1997^{14}$ & $\begin{array}{l}\text { Enalaprilat inhibited isoproterenol-induced LVH action on cardiomyocytes, partially prevented the LVH and decreased } \\
\text { the content of collagen fibers in rats. }\end{array}$ \\
Tan et al., 1992 & $\begin{array}{l}\text { Angiotensin-converting enzyme inhibition demonstrated promising myocardial remodeling effects in experimental } \\
\text { models of hypertensive heart disease. } \\
\text { Verapamil prevented the deleterious effects of isoproterenol in the myocardium of rats. This action was probably due to } \\
\text { the prevention of myocardial hypertrophy and collagen tissue proliferation. } \\
\text { Moexipril } 15 \text { mg once daily, administered for } 24 \text { weeks, resulted in a significant reversal of LVH in patients with es- } \\
\text { sential hypertension. } \\
\text { Losartan prevented more cardiovascular morbidity and deaths than did atenolol while inducing a similar reduction in } \\
\text { blood pressure and is better tolerated in humans. Losartan seemed to confer benefits beyond a reduction in blood pres- } \\
\text { sure. }\end{array}$ \\
Ferreira Filho et al., $2007^{23}$ & $\begin{array}{l}\text { Enalaprilat increased the regression of hypertrophy in the left ventricle but not in the diaphragm or the gastrocnemius } \\
\text { muscles. }\end{array}$ \\
\hline
\end{tabular}

1 demonstrate the relevance of angiotensin-converting enzyme (ACE) inhibitors ${ }^{14,15,22-24}$ and angiotensin antagonist ${ }^{25}$ treatment for cardiac hypertrophy regression.

\section{DISCUSSION}

\section{Regression of left ventricular hypertrophy}

The high prevalence of LVH and the high rate of complications of its condition necessitate a thorough understanding of the mechanisms involved in its etiology and development, as well as the importance of prevention and regression, to optimize and prevent the deleterious consequences. Thus, it is important to clarify the following issues, which are described below.

\section{Relationship between LVH regression and cardiovascu- lar morbidity and mortality}

Several published reports have provided data indicating that anti-hypertensive drugs promote ventricular hypertrophy regression and myocardial repair. In particular, ACE inhibitors have shown promising cardio-protective effects in experimental models of hypertensive heart disease; ${ }^{22}$ specifically, these inhibitors improve micro-vascular ischemia, ventricular function and arrhythmias. ${ }^{14-16,23-29} \mathrm{We}$ have previously reported that enalapril ${ }^{14}$ (ACE inhibitor) and verapamil ${ }^{23}\left(\mathrm{Ca}^{++}\right.$channel blocker) provide the same cardio-protector response in an isoproterenol-induced LVH model in rats. ${ }^{28}$

To evaluate the effects of LVH and its regression, a previous study evaluated 151 patients with hypertension and LVH progression detected by echocardiography. The patients were followed for an average of 10 years \pm 1.4 years, and the researchers noted a decrease in the non-fatal events rate following reduction of $\mathrm{LVH}$, even after correcting for other risk factors. Conversely, the occurrence of these events increased when cardiac hypertrophy increased or remained stable..$^{23}$

Another clinical investigation examined 430 patients with essential hypertension (also called primary or idiopathic hypertension) and related changes in the left ventricular mass with the occurrence of cardiovascular events. Treatments consisted of medication and lifestyle changes. At the 2 years and 9 months follow-up assessment, the prevalence of $\mathrm{LVH}$ by echocardiography was $26 \%$ per year, and the rate of cardiovascular events was $3.9 \%$ per year. For individuals who showed an improvement in $\mathrm{LVH}$, the rate of cardiovascular events was 1.58 events per 100 patients per year. In the groups that experienced no change or a worsening in $\mathrm{LVH}$, the rate of cardiovascular events was 6.27 events per 100 patients per year. These researchers also noted that this association did not depend on the initial ventricular mass, clinical parameters or monitored baseline blood pressure. Their final conclusion was that for primary hypertension, the decrease in ventricular mass during treatment is a favorable prognostic marker for subsequent morbid events.

\section{Relationship between anti-hypertensive drugs and LVH regression}

With the exception of minoxidil and hydralazine, which are peripheral vasodilators, the other anti-hypertensive drugs provided full or partial LVH regression. ${ }^{28}$ Not all classification, prospective and randomized studies that have evaluated the effectiveness of various drugs with respect to left ventricular mass reduction have reported evidence of a difference between their effects on LVH regression. ${ }^{23}$ 
However, in view of the different effects of the drugs, those drugs that depend on neural and humoral mechanisms, especially as reported in monotherapy studies, provide evidence that there may be several ways in which the drugs' properties could reduce ventricular mass. In the literature, there are few monotherapy treatment meta-analyses. In addition, different groups report contradictory results. ${ }^{23}$ Most studies have used anti-hypertensive drugs (i.e., betablockers and diuretics) and reported 5-8\% reductions of the left ventricular mass, while the use of ACE inhibitors and angiotensin AT1 blockers resulted in a 13\% reduction. The difference between different anti-hypertensive drugs regarding their ability to reverse LVH may be determined by neural and humoral factors. ${ }^{30}$

Because LVH regression is an important intermediate objective of anti-hypertensive therapy, several trials and meta-analyses have compared the effects of these drugs on ventricular hypertrophy, but the usefulness of these studies is limited due to inadequate designs and methodological problems. ${ }^{32}$ The PRESERVE (Prospective Randomized Enalapril Study Evaluating Regression of Ventricular Enlargement), ${ }^{33}$ LIVE (Indapamide Sustained Release Versus Enalapril) $^{34}$ and LIFE (Losartan Intervention for Endpoint in Hypertension $)^{25}$ studies represent a new generation of well-planned trials comparing different anti-hypertensive drugs. These investigations revealed that during regression of LVH, the effects of nifedipine and enalaprilat are similar (PRESERVE); indapamine has a stronger effect than does enalapril (LIVE); and losartan treatment has a stronger effect than atenolol (LIFE).

The findings of these three studies conflict with the findings of some previous meta-analyses, and as such, these researchers have suggested that the effects of antihypertensive drug must be evaluated individually on their important intermediate targets, such as LVH, with appropriate patient populations. The extrapolation of the LVH regression effects based on the anti-hypertensive drug classification may lead to clinical mistakes and needs to be carefully reconsidered. ${ }^{23}$

\section{Mechanisms besides the decreased hemodynamic over- load that may be responsible for $\mathrm{LVH}$ regression}

A decrease in blood pressure may reduce a ventricular mass. In addition to clinical studies, experimental studies have demonstrated that $\mathrm{LVH}$ prevention and/or regression is independent of blood pressure. For instance, our group investigated isoproterenol-induced LVH in albino rats, which typically leads to hypertrophy without an increase in the after-load, and reported LVH regression by gavage administration of enalapril ${ }^{15,16,28,31}$ and verapamil. ${ }^{23,30}$
Moreover, studies in spontaneously hypertensive rats, a rat strain commonly used in our laboratory ${ }^{35-39}$, demonstrated that although various anti-hypertensive drugs may control systemic hypertension, LVH may be influenced by many, but not all, anti-hypertensive agents. Alpha-methyldopa, captopril, beta-blockers and calcium channel blockers promote the regression of hypertrophy, while other drugs, such as hydralazine and minoxidil, reduce blood pressure without influencing ventricular hypertrophy. ${ }^{23}$

However, the development of LVH in arterial hypertension may be explained primarily by an increased pressure overload and ventricular wall tension. The ratio of ventricular mass to pressure is often weak, even in relation to blood pressure monitored every 24 hours. ${ }^{3}$ Notably, LVH may occur independently from changes in arterial pressure and be present even when hypertension does not develop. ${ }^{1}$ We may include the presence of others factors involved in this condition, such as lifestyle, anthropometric and demographic characteristics, genetic influences and neural and humoral factors. ${ }^{24}$

Furthermore, in vivo, in vitro and genetic studies indicate that LVH development and its regression depends not only on the hemodynamic overload but also on other genetic, neural and humoral factors. ${ }^{9}$ Humoral agents that may affect mitogenesis and non-myocyte cardiomyocytes have been identified; these agents include the renin-angiotensin system, local norepinephrine, endothelin, transforming growth factor, insulin-like growth factor, bradykinin, prostaglandins and nitric oxide. ${ }^{23}$ The direct relationship between high blood pressure and LVH development has been questioned due to the fact that LVH development and its regression depends not only on the hemodynamic overload, forcing a review of the mechanisms involved in LVH development, such as the role of the sympathetic nervous system, the renin-angiotensin system, genetic factors, endothelin and endothelium. ${ }^{1}$ It is important to remember that the pathogenesis of LVH includes angiotensin II receptors and membrane-stretched cardiomyocytes. ${ }^{2}$

Several publications have reported that although antihypertensive drugs show non-uniform effects on LVH, there are no concomitant proportional decreases in blood pressure..$^{13,20}$ Conversely, anti-hypertensive drugs have promoted different effects on $\mathrm{LVH}$, despite inducing similar reductions in blood pressure. ${ }^{4}$ Those assumptions lead us to consider other mechanisms involved in LVH regression that are independent of blood pressure reduction.

\section{Intrinsic properties of anti-hypertensives on LVH re- gression: beyond blood pressure?}

A decrease in cardiac mass may not depend only on daily arterial pressure measurement. ${ }^{23}$ Recently, Mayos 
et al. ${ }^{40}$ localized chromosome regions that harbor genetic variants that affect the diversity of electrocardiographic and echocardiographic LVH. They evaluated the genetic association of the Sokolow-Lyon voltage index and the Cornell product index, the septal thickness and the ventricular wall, ventricular dimensions and left ventricular mass in 868 members of 224 British households, all items were evaluated $\mathrm{n}$ pairs and together. Chromosomes 10 , 12 and 17 were the genetic loci involved and had the most important influence on $\mathrm{LVH}$, as detected by the electrocardiogram. ${ }^{23}$

Genetic factors may explain a substantial portion of the quantitative variability in the electrocardiographic and echocardiographic examinations due to hemodynamic and/ or hormonal factors. However, the quantitative differences in LVH, known as phenotypes, may also be the result of individual differences besides those produced by the various anti-hypertensive drugs (i.e., beyond blood pressure).

\section{CONCLUSION}

LVH is an important marker of poor prognosis. Current medical literature shows the direct relationship between LVH and mortality, as well as the relationship between LVH regression and decreasing mortality. The literature also provides evidence for hypertrophic variations in response to the effect of different anti-hypertensive drugs and differences in the hemodynamic patterns.

\section{ACKNOWLEDGEMENTS}

Our studies received financial support from NEPAS (Núcleo de Estudos, Pesquisas e Assessoria à Saúde da Faculdade de Medicina do ABC), Capes (Coordenação de Aperfeiçoamento de Pessoal de Nível Superior), and FAPESP (Fundação de Amparo a Pesquisa do Estado de São Paulo).

\section{REFERENCES}

1. Duarte DR, Minicucci MF, Azevedo PS, Matsubara BB, Matsubara LS, Novelli EL, et al. The role of oxidative stress and lipid peroxidation in ventricular remodeling induced by tobacco smoke exposure after myocardial infarction. Clinics. 2009; 64: 691-7.

2. Ieva R, Correale M, Di Biase M. A case of pseudo-hypertrophic cardiomyopathy: a congenital heart disease. Clinics. 2008;63:557-60.

3. Urbanek K, Quaini F, Tasca G, Torella D, Castaldo C, Nadal-Ginard $\mathrm{B}$, et al. Intense myocyte formation from cardiac stem cells in human cardiac hypertrophy. Proc Natl Acad Sci U S A. 2003;100:10440-5.

4. Zamo FS, Lacchini S, Mostarda C, Chiavegatto S, Silva IC, Oliveira EM, et al. Hemodynamic, morphometric and autonomic patterns in hypertensive rats - Renin-Angiotensin system modulation. Clinics. 2010;65:85-92.

5. Meneghini A, Ferreira C, Abreu LC, Ferreira M, Ferreira Filho C, Valenti VE, et al. Cold stress effects on cardiomyocytes nuclear size in rats: light microscopic evaluation. Rev Bras Cir Cardiovasc. 2008;23:530-3.

6. Meneghini A, Ferreira C, de Abreu LC, Valenti VE, Ferreira M, Filho $\mathrm{CF}$, et al. Memantine prevents cardiomyocytes nuclear size reduction in the left ventricle of rats exposed to cold stress. Clinics. 2009;64:921-6.

7. Daud FV, Murad N, Meneghini A, Ferreira M, Ferreira Filho C, Abreu LC, et al. Fluoxetine effects on mitochondrial ultrastructure of right ventricle in rats exposed to cold stress. Rev Bras Cir Cardiovasc. 2009; 24:173-9.

8. Ferreira M, Ferreira C, de Abreu LC, Valenti VE, Murad N, Meneghini A, et al. Myocardium tissue changes caused by electrical transthoracic discharges in rats. Int Arch Med. 2009;2:31.

9. Meneghini A, Ferreira C, Abreu LC, Valenti VE, Ferreira M, Murad N. Electric countershock and cold stress effects on liver and adrenal gland. 2010;65:291-6.
10. Rocha AM, Salemi VM, Lemos Neto PA, Matsumoto AY, Pereira VF, Fernandes $\mathrm{F}$ et al. Endothelial and non-endothelial coronary blood flow reserve and left ventricular dysfunction in systemic hypertension. Clinics. 2009;64:327-35.

11. Zanati SG, Mouraria GG, Matsubara LS, Giannini M, Matsubara BB. Profile of cardiovascular risk factors and mortality in patients with symptomatic peripheral arterial disease. Clinics. 2009;64:323-6.

12. Cayli M, Kanada i M, Akpinar O, Usal A, Poyrazo lu H. Diastolic function predicts outcome after aortic valve replacement in patients with chronic severe aortic regurgitation. Clin Cardiol. 2009;32: E19-23

13. Madu EC, D'Cruz IA. The vital role of papillary muscles in mitral and ventricular function: echocardiographic insights. Clin Cardiol. 1997;20:93-8

14. Costa EA, Luna Filho B, Póvoa R, Ferreira Filho C, Murad N, Ferreira $\mathrm{M}$, et al. Enalaprilat in the prevention of left ventricular hypertrophy induced by isoproterenol. Arq Bras Cardiol. 1997;69:35-9.

15. Ferreira Filho C, Luna Filho B, Riera AP, Meneghini A, Ferreira C. Study of the Effects of Enalaprilate Induced by Isoproterenol due Myocardium, Diaphragm and Gastrocnemius. Einstein. 2007;5:321-5.

16. Bregagnollo EA, Okoshi K, Bregagnollo IF, Padovani CR, Okoshi MP, Cicogna AC. Effects of the prolonged inhibition of the angiotensinconverting enzyme on the morphological and functional characteristics of left ventricular hypertrophy in rats with persistent pressure overload. Arq Bras Cardiol. 2005;84:225-32.

17. Muiesan ML. Left ventricular hypertrophy: a new approach for fibrosis inhibition. J Hypertens. 2002;20:611-3.

18. Verdecchia P, Angeli F, Achilli P, Castellani C, Broccatelli A, Gattobigio $\mathrm{R}$, et al. Echocardiographic left ventricular hypertrophy in hypertension: marker for future events or mediator of events? Curr Opin Cardiol. 2007;22:329-34. 
19. Frohlich ED. Fibrosis and ischemia: the real risks in hypertensive heart disease. Am J Hypertens. 2001;14:194S-199S.

20. Koren MJ, Devereux RB, Casale PN, Savage DD, Laragh JH. Relation of left ventricular mass and geometry to morbidity and mortality in uncomplicated essential hypertension. Ann Intern Med. 1991;114:34552.

21. Levy D, Garrison RJ, Savage DD, Kannel WB, Castelli WP. Prognostic implications of echocardiographically determined left ventricular mass in the Framingham Heart Study. N Engl J Med. 1990;322:1561-6.

22. Tan LB, Brilla C, Weber KT. Prevention of structural changes in the heart in hypertension by angiotensin converting enzyme inhibition. $\mathrm{J}$ Hypertens Suppl. 1992;10:S31-4.

23. Bombig MT, Luna Filho B, Costa EA, Leite DA, Póvoa R, Murad N, et al. Effect of verapamil on left ventricular hypertrophy induced by isoproterenol. Arq Bras Cardiol. 1996;67:81-5.

24. Sayegh F, Topouchian J, Hlawaty M, Olzewska M, Asmar R. Regression of left ventricular hypertrophy with moexipril, an angiotensin-converting enzyme inhibitor, in hypertensive patients. Am J Ther. 2005;12:3-8.

25. Dahlöf B, Devereux RB, Kjeldsen SE, Julius S, Beevers G, de Faire U, et al. Cardiovascular morbidity and mortality in the Losartan Intervention For Endpoint reduction in hypertension study (LIFE): a randomised trial against atenolol. Lancet. 2002;359:995-1003.

26. Klaus D. Regression of left heart hypertrophy in arterial hypertension: principles, experimental and clinical findings. Z Kardiol. 1985;74:15369.

27. Zusman R. Patients with uncontrolled hypertension or concomitant hypertension and benign prostatic hyperplasia. Clin Cardiol. 2004;27:639.

28. Póvoa R, Luna Filho B, Ferreira C, Antonangelo L, Capellozzi V, Murad N. Left ventricular hypertrophy--its reversion speeded up by enalaprilat. Rev Port Cardiol. 1997; 16:57-60.

29. Ferreira C, Luna Filho B, Póvoa R, Antonangelo L, Capellozi V, Murad $\mathrm{N}$, et al. The expression of nucleolar organizer regions in left ventricular hypertrophy. Rev Port Cardiol. 1997;16:53-5.
30. Póvoa R, Manzoli MT, Ferreira C, Murad N, Simões M, Ferreira C, et al. Myocardial hypertrophy due to isoproterenol. The preventive action of verapamil. Rev Port Cardiol. 1995;14:847-51.

31. Póvoa R, Costa E, Luna Filho B, Murad N, Costa A, Simões M, et al. Left ventricular hypertrophy: its prevention with enalapril. Rev Port Cardiol. 1995;14: 779-81.

32. Kannel WB, Gordon T, Castelli WP, Margolis JR. Electrocardiographic left ventricular hypertrophy and risk of coronary heart disease. The Framingham study. Ann Intern Med. 1970;72:813-22.

33. Palmieri V, Dahlöf B, DeQuattro V, Sharpe N, Bella JN, de Simone G, et al. Reliability of echocardiographic assessment of left ventricular structure and function: the PRESERVE study. Prospective Randomized Study Evaluating Regression of Ventricular Enlargement. J Am Coll Cardiol. 1999;34:1625-32.

34. Gosse P, Dubourg O, Gueret P. Regression of left ventricular hypertrophy with echocardiography: some lessons from the LIVE study. J Hypertens. 2003;21:217-21.

35. Valenti VE, Ferreira C, Meneghini A, Ferreira M, Murad N, Ferreira Filho C, et al. Evaluation of baroreflex function in young spontaneously hypertensive rats. Arq Bras Cardiol. 2009;92:205-15.

36. Valenti VE, Imaizumi C, de Abreu LC, Colombari E, Sato MA, Ferreira C. Intra-strain variations of baroreflex sensitivity in young Wistar-Kyoto rats. Clin Invest Med. 2009;32:E251.

37. Cisternas JR, Valenti VE, Alves TB, Ferreira C, Petenusso M, Breda JR, et al. Cardiac baroreflex is already blunted in eight weeks old spontaneously hypertensive rats. Int Arch Med. 2010;3:2.

38. Valenti VE, Abreu LC, Colombari E, Sato MA, Ferreira C. Baroreflex sensitivity variability in juvenile spontaneously hypertensive rats. Cardiovasc J Afr. 2010;21:132-8.

39. Valenti VE, de Abreu LC, Imaizumi C, Petenusso M, Ferreira C. Strain differences in baroceptor reflex in adult wistar kyoto rats. Clinics. 2010;65:203-8.

40. Mayosi BM, Avery PJ, Farrall M, Keavney B, Watkins H. Genomewide linkage analysis of electrocardiographic and echocardiographic left ventricular hypertrophy in families with hypertension. Eur Heart J. 2008;29:525-30. 